\title{
A odontologia e a violência doméstica contra mulheres: diagnóstico e conduta
}

A violência doméstica é caracterizada por situações em que as vítimas são submetidas a agressões psicológicas, sexuais, materiais ou físicas que ocorrem, muitas vezes, por pessoas de seu convivio familiar. Tornou-se um problema de saúde pública. Assim, cabe aos profissionais da área de saúde atuar nesse processo de valorização a vida. Este estudo tem como objetivo apresentar o papel do Cirurgião-Dentista em identificar lesões orofaciais e sinais decorrentes de violência doméstica contra mulher, também apontar a conduta do profissional mediante a esses casos. Foi realizado um estudo qualitativo, através de revisão bibliográfica. Como resultado, a maior prevalência de lesões na cabeça e pescoço mostram a importante atuação do Cirurgião-Dentista e a necessidade desses profissionais estarem preparados para atender, diagnosticar, tratar e notificar, essas vítimas. Pois o Cirurgião-Dentista pode se deparar, em seus atendimentos, com pacientes que são vítimas não assumidas. Visando isso, foram apresentados os sinais e sintomas que juntamente com outros fatores podem levar a identificação dessas vítimas. Para que se descubra o que há por trás de tais lesões. Desta forma, o profissional além de diagnosticar e tratar deve utilizar a notificação compulsória como uma importante ferramenta de combate e de garantia de direitos. Mas, para isso, é necessária uma melhor preparação destes, com intuito de formar não só profissionais melhores, como mais humanos.

Palavras-chave: Odontologia; Violência Doméstica; Notificação Compulsória.

\section{Dentistry and domestic violence against women: diagnosis and conduct}

\begin{abstract}
Domestic violence is characterized by situations in which victims are subjected to psychological, sexual, material or physical aggression that occur, often, by people in their family life. It has become a public health problem. Thus, it is the responsibility of health professionals to act in this process of valuing life. This study aims to present the role of the Surgeon-Dentist in identifying orofacial lesions and signs resulting from domestic violence against women, also to indicate the conduct of the professional through these cases. A qualitative study was carried out through a bibliographic review. As a result, the higher prevalence of head and neck injuries shows the important performance of the Dentist and the need for these professionals to be prepared to attend, diagnose, treat and notify these victims. Because the Dentist may come across, in his care, with patients who are unassuming victims. Aiming at this, the signs and symptoms that along with other factors may lead to the identification of these victims were presented. To discover what lies behind such lesions. In this way, the professional, besides diagnosing and treating, must use compulsory notification as an important tool to combat and guarantee rights. But for this, better preparation of these is necessary, in order to train not only better professionals, but more human.
\end{abstract}

Keywords: Dentistry; Domestic violence; Compulsory Notification.

Topic: Odontologia Social e Preventiva

Reviewed anonymously in the process of blind peer.
Received: 24/06/2019

Approved: 12/09/2019

Eloise Dayane Martins da Silva (iD

Faculdade de Macapá, Brasil

http://lattes.cnpq.br/9306619728866924

http://orcid.org/0000-0002-2735-7056

eloise.martins5@gmail.com

Referencing this:

SILVA, E. D. M.. A odontologia e a violência doméstica contra mulheres: diagnóstico e conduta. Scire Salutis, v.9, n.3, p.22-32, 2019. DOI: http://doi.org/10.6008/CBPC2236-9600.2019.003.0004 


\section{INTRODUÇÃO}

A violência doméstica é caracterizada por situações em que as vítimas são submetidas a agressões psicológicas, sexuais, materiais ou físicas que ocorrem, muitas vezes, por pessoas de seu convívio familiar. Tornou-se um problema de saúde pública. Desta forma, cabe aos profissionais da área de saúde atuarem nesse processo de valorização a vida. Os Cirurgiões-Dentistas são fundamentais na assistência e tratamento dessas vítimas, visto que, as lesões na face e boca são as mais frequentes.

O intuito deste trabalho é chamar atenção dos profissionais da área odontológica para um atendimento mais humanizado, com atenção voltada a essa problemática. Para que seja possível identificar lesões tanto orofaciais, como outras perceptíveis em outros membros, até mesmo, usados como formas de defesas. Sabendo proceder frente a casos assim, não se limitando apenas ao tratamento das lesões apresentadas como sua 'queixa principal', passando despercebida a real etiologia delas.

Lesões como: lacerações de lábios e da língua, palato duro e palato mole, gengiva alveolar, contusões, presença de queimaduras, machucados no canto da boca, acompanhadas ou não de hematomas e perdas de elementos dentais; sejam não só tratados, como também identificados como possíveis sinais de violência doméstica. O Cirurgião-Dentista é o profissional na área da saúde com maiores chances de deteç̧ão dessas lesões e de extrema importância na atuação da reabilitação física dessas vítimas.

Através de revisão de literatura, visou-se mostrar o fundamental papel do Cirurgião-Dentista na identificação de lesões, tanto orofaciais, como na cabeça, pescoço ou membros; sinais decorrentes de violência doméstica contra mulher; a conduta profissional; também, conceituando a violência, histórico, seus tipos e avanços.

\section{METODOLOGIA}

Para a realização desse trabalho foi feito um estudo qualitativo, através de revisão bibliográfica sistematizada de artigos e livros publicados no Brasil. A pesquisa foi realizada através de sites de buscas como Scielo, Google Acadêmico e Lilacs, sendo utilizados os seguintes termos para pesquisa: 'violência', 'violência doméstica', 'odontologia' e 'violência contra mulher', sendo também um dos critérios de inclusão e artigos publicados no período dos últimos treze anos.

\section{RESULTADOS E DISCUSSÃO}

\section{Contexto violência}

A violência é qualquer forma intencional do uso do poder ou da força, contra si mesmo ou contra outra pessoa, ou um grupo. No que diz respeito à violência contra mulheres, é toda ação de violência ao sexo feminino que resulte em sofrimento físico ou danos, psicológico e sexual; incluindo coerção ou privação da liberdade, no âmbito público ou privado (LEITE et al., 2015).

Dentre todos os tipos, destacamos a violência doméstica contra mulher, ou seja, violência que ocorre dentro de seu próprio lar (simbolicamente), no qual o agressor possa ser alguém que habite na mesma 
residência que a vítima, ou mesmo não coabitando, seja companheiro (a) ou ex-companheiro (a). Oliveira et al. (2015) afirma ainda que sempre existiu esse tipo de violência, de forma multifatorial, porém ligada principalmente a questão de gênero.

Há múltiplas formas em como a violência doméstica é exercida. Temos violência patrimonial, quando há destruição de objetos, bens materiais ou documentos; violência moral, que é qualquer conduta que caracterize injúria, calúnia ou difamação; a violência psicológica e emocional que consiste em críticas, menosprezo, desprezo, insultos ou humilhações a vítima, através de comportamentos ou palavras; depreciação da aparência da mesma, ameaças, perseguições, amedrontamento, intimidação. Em relação a violência sexual, é toda imposição de práticas de cunho sexual imposto contra a vontade da vítima, utilizando a coerção e até mesmo a força física para a obrigar. Na violência física, é utilizada a força física com intenção de causar algum dano físico, com ou sem marcas evidentes, tais como: murros, tapas, chutes, puxar o cabelo, empurrões, atropelamentos, que podem resultar em lesões leves ou graves e até mesmo a morte da vítima. Em muito dos casos, esses tipos de violência são praticados em conjunto (FONSECA et al., 2012).

\section{Uma breve volta ao passado}

O problema da violência doméstica contra mulheres infelizmente é um retrato de uma cultura enraizada desde os tempos antigos, um dos fatores por ser banalizada e ignorada pela sociedade por anos. Haja vista que, é a real exposição tanto da força física, como o poder masculino e de toda a história de desigualdades socioculturais entre homens e mulheres. Ressaltando que por meio da estereopatização desses papéis, intensificam a violência (OLIVEIRA et al., 2015).

Através das lutas e conquistas de seus direitos, houve uma quebra nos papéis 'históricos', do qual a mulher só servia para cuidar do lar, ser mãe, cuidar do marido. A violência surgiu como forma de repressão para que a mulher volte a ocupar o "seu lugar" (LEITE et al., 2015). A frase popularmente conhecida "em briga de marido e mulher não se mete a colher", por tempos, foi levada como um dogma a ser seguido. Onde ninguém interferia nos conflitos e intimidades das famílias, até mesmo com indícios claros de que havia violência física. O poder judiciário se absteve por muito tempo (ESSY, 2017).

Somente na Conferência Mundial sobre os direitos humanos das Nações Unidas, que ocorreu em Viena, no ano de 1993, a violência contra mulheres foi reconhecida como um obstáculo aos ideais de igualdade e ao desenvolvimento da paz entre os seres humanos (LEITE et al., 2015). Foi proclamado então em 1994, pela Convenção Interamericana para Prevenir, Punir e Erradicar a Violência Doméstica, documento este em vigor no Brasil especificamente sobre violência contra mulher. Na qual, também foi considerada a violência doméstica contra mulheres uma violação aos direitos humanos, baseando-se no fato da pessoa ser do sexo feminino. Convenção essa que em 1995 foi ratificada pelo Brasil, tornando-se necessário para qualquer brasileira em situação de risco (ESSY, 2017).

A Convenção Sobre a Eliminação de Todas as Formas de Descriminalização contra as Mulheres, conhecida como Convenção das Mulheres, em 1979, adotada pela Assembleia Geral da Organização das Nações Unidas. Entrando em vigor em 1981, foi o primeiro instrumento de proteção internacional, dispondo 
amplamente sobre os direitos humanitários das mulheres, abrangendo áreas como saúde, trabalho, educação, direitos políticos e civis. Desta forma, teve como intenção a promoção dos direitos das mulheres e reprimenda da discriminação contra elas. Contudo, a Convenção só foi ratificada integralmente em 1994 e promulgada no Brasil somente em 2002, pelo então Presidente da República (ESSY, 2017).

\section{Avanços no âmbito legislativo}

A criação de Juizados Especiais, através da Lei no 9.099/1995, foi o primeiro grande passo que a Constituição Federal ofereceu no seu Artigo 98 Inciso I, para julgar crimes de menor potencial ofensivo. Representando uma revolução no sistema processual penal brasileiro. Entretanto, o juizado possui medidas despenalizadoras, ou seja, podendo utilizar aplicação de pena de multas ou pena de restrição de direitos.

Em 1985, foi implementado em São Paulo a primeira Delegacia Especializada no Atendimento à Mulher (DEAMs). Atualmente, há um total de quase 400 Delegacias de Atendimento especializado, o órgão faz parte da Polícia Civil (MORAES et al., 2012). Com a elevação dos índices da violência contra mulheres e as baixas condenações, criou-se a Lei $\mathrm{n}$-10.455/2002, a medida cautelar, que permite que o agressor seja afastado da vítima; e a Lei no 10.886/2004, acrescentando a lesão corporal leve, dessa forma aumentando a pena para a violência doméstica (ESSY, 2017).

Mas, ainda faltava uma lei que protegesse e amparasse a mulher vítima de violência doméstica, com tratamentos e punições diferenciadas para cada caso. Por conta do desfavorecimento que a legislação ainda apresentava, pois regulava esse tipo de ação penal, muitas mulheres ainda tinham suas denúncias/vozes caladas (ESSY, 2017).

A luta das mulheres desde o começo para obter os seus direitos foi constante e cheia de obstáculos. Da mesma forma que, Maria da Penha lutou para que seu agressor e então marido fosse julgado. Após vários tipos de violências e tentativas de homicídios sofridas, as quais resultaram na paraplegia da vítima. Inclusive fez com que seu caso ganhasse repercussão nacional e internacional. Tornou-se então símbolo da luta contra violência doméstica. Neste caso, o Brasil foi responsabilizado pela Comissão Internacional dos Direitos Humanos, em 2001, por tolerância, negligência e omissão (CARNEIRO et al., 2012).

Em 2006, criou-se então a Lei no 11.340, batizada de Lei Maria da Penha. Criando-se assim, mecanismos para coibição da violência doméstica contra a mulher e punição ao agressor, visto que, não se pode empregar penas como pagamento de cestas básicas pelo agressor ou medida alternativa à prisão. Regulamentando os direitos assegurados internacionalmente e que foram ratificados pelo Brasil através de tratados. Impondo desta forma a legitimação de políticas públicas a fim de resguardar os direitos humanos das mulheres (CARNEIRO et al., 2012). A equipe diversificada, montada pelos juizados especiais criados com a Lei Maria da Penha, conta com atendimentos de profissionais além da área jurídica, como os da área da saúde (ESSY, 2017).

\section{Ciclo vicioso}

No caso da violência doméstica contra mulher, há um ciclo o qual deve ser observado, pois segue um 
padrão de agressão. A primeira fase, chamada de Acúmulo de Tensão, há um nervosismo e estresse resultando em um espancamento leve e a mulher tende amenizar e 'evitar' mais agressões, seguindo um comportamento 'correto'. Explosão é a segunda fase, onde há o espancamento grave, falta de controle; nessa fase, algumas mulheres ainda chegam a chamar a polícia. Até que vem a fase da Lua de Mel, caracterizada como terceira fase, onde o homem se mostra arrependido, carinhoso, com promessas de mudança de comportamento. Contudo, o ciclo recomeça da primeira fase (LUCENA et al., 2016).

A importância para que os profissionais da área da saúde tenham conhecimento a respeito desse assunto, visto que, mulheres em situações de violência, tendem a utilizar os serviços de saúde com maior frequência. Concluindo dessa forma, uma boa parte de pacientes pode sofrer ou já terem sofrido algum tipo de violência. Uma vez que, a lesão corporal procedente de violência conjugal é a maior causa de lesão corporal nos serviços de emergência, justapondo-se aos acidentes automobilísticos (PEDROSA et al., 2011).

\section{Sinais e sintomas da violência doméstica contra mulher em vítimas não declaradas}

Um dos primeiros questionamentos dos profissionais quando se deparam com um caso de violência doméstica é o do porquê a vítima não conta o que está acontecendo. Há explicações diversas, como por exemplo, a vítima se sente envergonhada, humilhada, culpada, com medo ou receio pela sua segurança própria ou da sua família, já teve alguma experiência negativa ou quer protege-lo por razões de dependência afetiva ou financeira, há casos também em que o agressor a acompanha e não deixa a sós com os profissionais da saúde (COLOMBO, 2012). Santana et al. (2011) ressalta em sua pesquisa que $57,7 \%$ das mulheres foram agredidas pelos seus companheiros e 31,7\% por seu ex-companheiro.

Contudo, não cabe aos profissionais da saúde fazerem julgamentos a respeito e sim, um atendimento humanizado com escuta qualificada, criando uma relação de confiança com a paciente e a empoderando para que busque por seus direitos. Ainda no tempo que estamos, há pouco conhecimento por partes dos profissionais a respeito do tema ou até mesmo crenças antigas que persistem até os dias de hoje, dificultando essa relação. Devem compreender que não estão com os agressores porque gostam de ser agredidas, e sim, por alguma dependência, ou por temer pela sua família, ou acreditar que é um problema privado, sem direito de intrometer-se. Porém, a violência doméstica contra mulheres é um problema de saúde pública (CURITIBA, 2008).

As vítimas de violência são usuárias constantes dos serviços de saúde, às vezes com queixas vagas e crônicas, sem relatar a agressão sofrida, consideradas até como poliqueixosas e hipocondríacas. Ainda assim, as consequências da violência repercutem nos serviços de saúde, através dos custos gerados pelos atendimentos e na complexidade de alguns tratamentos (TORVANOI et al., 2011). Pois na maioria dos casos, as vítimas necessitam de tratamento e acompanhamento multidisciplinar, onde além da odontologia, psicologia e terapia médica, há assistência social e tutela do Estado para resguardar seus direitos (GARBIN et al., 2006).

Em relação a odontologia, a violência física é o tipo mais frequente a ser diagnosticado. As áreas de cabeça e pescoço, conforme mostra a Figura 1, são as mais acometidas. A 'preferência' dessas regiões se dá 
ao caráter simbólico de humilhação e vergonha, nesse caso o agressor realmente quer que as lesões apareçam, uma forma de intimidar e eliminar a estima da vítima (GARBIN et al., 2006).

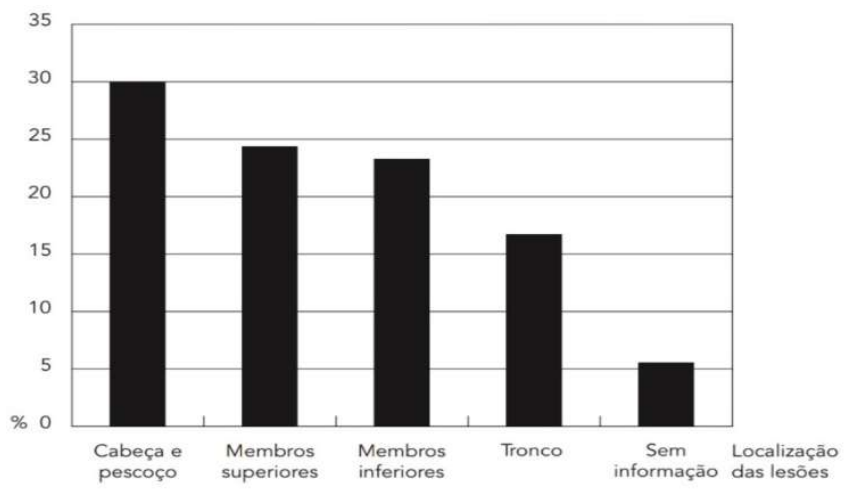

Figura 1: Percentual do total de lesões analisadas nos laudos médicos-legais de acordo com as regiões do corpo lesionadas. Fonte: Garbin et al. (2006).

Na Figura 1, Garbin et al. (2006) mostra o resultado que obteve em sua pesquisa, onde a área de cabeça e pescoço foi a de maior prevalência de lesões (30\%), seguido por membros superiores $(24,4 \%)$ e inferiores $(23,3 \%)$ e por fim, tronco $(16,7 \%)$, respectivamente. Silva et al. (2010) em estudo semelhante obteve resultados de $39,1 \%$ e $28,7 \%$, respectivamente, em diversos traumatismos que acometiam a região da cabeça e pescoço em mulheres vítimas de violência. As lesões físicas são classificadas como de natureza leve ou grave de acordo com o Código Penal Brasileiro. Na lesão corporal de natureza leve, não há grandes injúrias à integridade corporal da vítima, conforme se observa na Figura 2 (GARBIN et al., 2006).

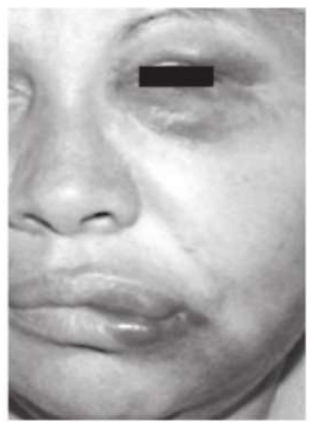

Figura 2: Do lado esquerdo da face, equimoses nas regiões periorbitária, labial e submandibular.

Fonte: Silva et al. (2010).

Dentre essas lesões estão: hematomas, equimoses (infiltração de sangue na malha de tecidos do organismo, devido à ruptura de capilares) e as fraturas dentárias de extensões pequenas. Conforme mostrado na Figura 2, onde foram constatadas na vítima duas lesões contusas na face, tendo como características: Uma lesão de equimose na região periorbitária esquerda e outra na região dos lábios e submandibular esquerda, com edema associado envolvendo toda a hemiface, sem comprometimento dentário e sem fraturas nas regiões (SILVA et al., 2010).

Já em relação à lesão corporal de natureza grave, temos fraturas maxilomandibulares que resultem em incapacidade para ocupações habituais (comer, falar etc.) por mais de 30 dias; avulsão dentária; perdas dentárias decorrentes de fratura radicular ou coronorradicular; perigo de vida; ou qualquer outra situação que cause debilitação permanente das funções mastigatórias e/ou fonética, ou que até mesmo 
comprometam a estética dentária durante o sorriso ou da fala de forma definitiva; ou nos casos de deformidade permanente, nos quais, lesões nos tecidos moles da face e que comprometam a estética, presença de cicatrizes ou por paralisia dos músculos da expressão facial (GARBIN et al., 2006).

Esses traumas faciais podem ser considerados uma das agressões mais devastadoras devido às consequências emocionais e a possibilidade de deformidades. Santana et al. (2011) em sua pesquisa mostrou que $72,9 \%$ das fraturas foram na região mandibular, seguido pela região zigomático-orbital 24,0\%; na maxila o resultado foi de $13,5 \%$ e tanto na área nasal como na cranial, o resultado foi de $2,1 \%$. Na Figura 3, temos uma fratura Parassinfisária em mulher decorrente de violência doméstica, com tratamento cirúrgico para a redução e fixação (CAMARGO et al., 2012).

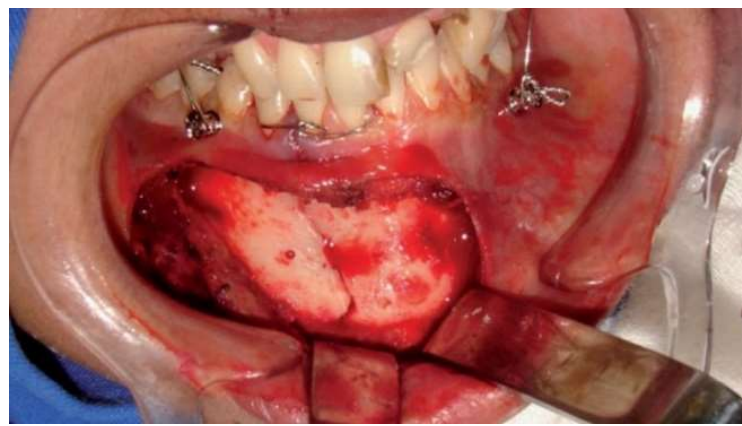

Figura 3: Acesso cirúrgico com visualização da área fraturada. Fonte: Camargo et al. (2012).

Conforme se observa na Figura 3, em relação à região anatômica, a fratura Parassinfisária é a que ocorre na região entre a linha média da mandíbula e linha vertical na distal do canino. Camargo et al. (2012) alerta ainda para os sinais e sintomas apresentados por fraturas: dor, edema as vezes pode estar associado, mobilidade óssea no local da fratura; no caso da mandíbula, ainda pode incluir: limitação dos movimentos, alteração na oclusão dentária, assimetria facial, hiperatividade das glândulas salivares, crepitação e em fraturas condilares bilaterais pode haver o retroposicionamento mandibular.

Outros sinais que não se podem deixar passar despercebido, em alguns casos de violência sexual, também podem resultar em lesões traumáticas em tecidos moles da cavidade oral, como lacerações dos frênulos linguais ou labiais, causados pela tentativa do agressor de satisfazer seu libido através do sexo oral, associado ou não a outras práticas sexuais. Manifestações como edema, inflamações, perfurações, irritação, rupturas ou arranhões também devem ser levados em consideração. Importante ressaltar que as manifestações primárias e até mesmo secundárias de Doenças Sexualmente Transmissíveis (DST/AIDS), podem ocorrer na cavidade oral, entre elas estão: herpes genital, candidíase, gonorreia, sífilis, condiloma acuminado e a AIDS. Nesses casos, o diagnóstico é confirmado através de exames clínicos e laboratoriais (ANTUNEZ et al., 2013).

Há sintomas psicossomáticos que podem ser identificados através de uma correta anamnese, onde insônia, irritabilidade, falta de concentração e pesadelos constantes podem ser indicativos de estresse póstraumático (principal transtorno psiquiátrico ligado a acidentes e episódios de violência). Outras alterações psicológicas como crise de pânico, medo, ansiedade, confusão, choque, sentimento de inferioridade, de insegurança e fracasso, baixa autoestima, depressão, culpa, fobias, tentativas de suicídio, auto reprovação, 
uso de drogas e álcool de forma abusiva, desordens alimentares/obesidade (COLOMBO, 2012).

Além desses indícios, Garbin et al. (2006) em sua pesquisa identificou $24,4 \%$ lesões em membros superiores e $23,3 \%$ em membros inferiores. Santana et al. (2011) em estudo semelhante observou que a maioria das vítimas apresentavam lesões em mais de uma região do corpo, 28,2\% apresentavam lesões nos membros superiores. Esse elevado número de agressões em regiões como mãos, braços, ombros, antebraços e punhos e até mesmo em regiões de coxas, pernas, pés, quadril; podem representar comportamento defensivo por parte da vítima, na tentativa de impedir ou minimizar a agressão, visto que, a maioria dos agressores buscam através de golpes de socos, chutes, tapas etc., desfigurar a face da vítima.

Através desses sinais e sintomas demonstrados, é possível observar a gravidade da violência doméstica e a real necessidade de que os Cirurgiões-Dentistas estejam aptos a identificar mulheres em situações de violência. Ou seja, o CD é de extrema importância, visto que, as maiores incidências de lesões são na região de cabeça e pescoço. Desta forma, cabe ao profissional o fundamental papel de primeiramente atender de forma integral e humanizada, diagnosticar, fazer as orientações necessárias, fazer a notificação compulsória, o correto preenchimento dos prontuários e o encaminhamento das mulheres em situações de violência aos serviços de assistência especializados, e claro, no tratamento das lesões (FIGUEIREDO et al., 2012).

\section{Atuação do cirurgião-dentista referente a casos de violência doméstica contra mulheres}

Como visto, o Cirurgião-Dentista é um dos profissionais da área da saúde que tem maiores chances de deparar-se com pacientes vítimas de violência doméstica. Desta forma, é obrigação do dentista ter conhecimento a respeito das normas e leis sobre a conduta adequada a ser seguida (SALIBA et al., 2007). Nos casos de violência doméstica contra mulher, as vítimas sofrem preconceito pelos profissionais quando buscam ajuda, até mesmo dos profissionais da área da saúde, pois ainda se acredita que a vítima é a culpada pelas agressões, sendo um dos fatores pelas quais não revelam a real etiologia das lesões. Dessa forma, é de extrema importância o acolhimento humanizado e diferenciado, respeitando sempre o trauma sofrido pela vítima. Ou seja, o acolhimento tem que ser mais que apenas uma prestação de serviço, pois ele é o vínculo entre a paciente/vítima e o serviço de saúde (LOPES, 2016).

\section{Notificação como importante ferramenta de combate}

De acordo com Torvanoi et al. (2011), um dos principais entraves é em relação ao conhecimento dos profissionais sobre a Notificação Compulsória e até mesmo sobre a violência doméstica. Como pode ser observado na Figura 4. Ainda segundo a pesquisa feita pelos autores, entre 180 Cirurgiões-Dentistas, 47\% não recebeu orientação a respeito na graduação, como constatado na Figura 4. Em consequência, na mesma pesquisa aponta que $64 \%$ desses profissionais não se consideravam aptos a diagnosticar casos de violência contra mulher (TORVANOI et al., 2011). 


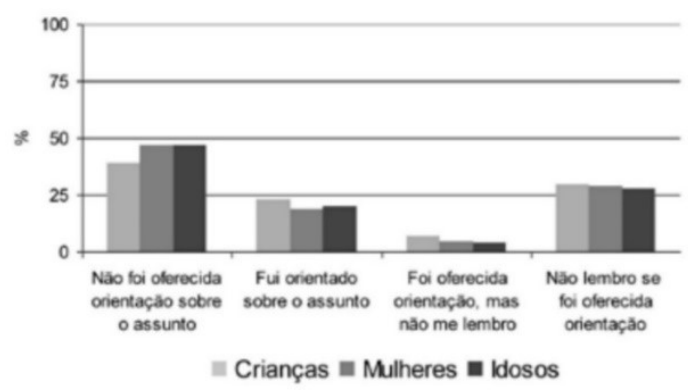

Figura 4: Instruções sobre violência doméstica recebidas na graduação. Fonte: Torvanoi et al. (2011).

Em 24 de novembro de 2003, foi promulgada a Lei n. 10.778 , a qual estabelece a obrigatoriedade da Notificação Compulsória, em casos suspeitos ou confirmados de violência de qualquer tipo contra a mulher, atendidos em serviços de saúde públicos ou privados, em território nacional. Através dos casos notificados, que esse tipo de violência ganha visibilidade, permitindo o dimensionamento epidemiológico do problema e a criação de políticas públicas efetivas para a prevenção. No artigo 66 da Lei n.․․ 3.688/41, enuncia que a omissão do profissional de saúde que não comunicar o crime do qual tenha tomado conhecimento por meio do seu trabalho, considerado contravenção penal, podendo acarretar em pena pecuniária (SALIBA et al., 2007).

Já no Código de Ética Odontológico não aborda explicitamente sobre a violência doméstica, contudo no artigo 5으, incisivo V, constitui deveres fundamentais do Cirurgião-Dentista: zelar tanto pela saúde como pela dignidade de seus pacientes. De acordo Silva et al. (2010), quando há suspeita através de lesões ou confirmação de que a paciente é uma vítima de violência doméstica, a notificação deve ser realizada, de forma sigilosa, utilizando o Código Internacional de Doenças (CID-10), em ficha padrão produzida pelo Sistema de Informação de Agravos de Notificação, conforme mostra a Figura 5.

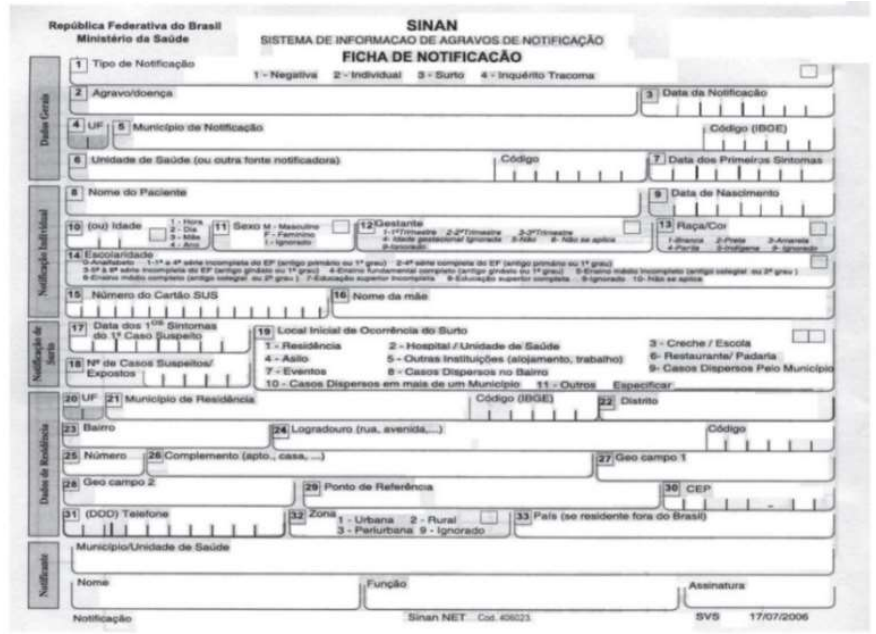

Figura 5: Ficha destinada a notificação compulsória. Fonte: Silva et al. (2010).

Após o preenchimento com todos os dados solicitados, a ficha deve ser encaminhada ao serviço de referência sentinela ou ao órgão de Vigilância Sanitária do município, conforme estabelecido no Decreto n.으 5.099/04, que regulamenta a Lei no 10.778. Importante ressaltar que os registros documentais das lesões e dos atendimentos efetuados são previstos na Lei Maria da Penha, o uso dos laudos e prontuários como provas (SILVA et al., 2010). 
Exames complementares podem e devem ser solicitados, para o registro documental. O CirurgiãoDentista deve realizar o registro detalhado das lesões, em tecidos moles e duros, identificando: a natureza das lesões, coloração, extensão; se há envolvimento de dentes, se sim, quais elementos, quantidade e quais faces dentárias foram afetadas; o tempo que foi produzido. Esses dados todos deverão ser registrados no prontuário do paciente. Que, aliás, tem direito ao acesso de dados contidos em seu prontuário; as autoridades também podem requisitar dados relacionados ao atendimento, caso seja instaurado um procedimento policial, ajudando no processo, proporcionando ao perito estabelecer conexões entre a violência sofrida e as lesões identificados e/ou tratadas pelo dentista (SILVA et al., 2010).

Em casos onde há lesões graves com risco de vida; queimaduras de graus elevados; hemorragias (boca, na face); lacerações grandes; traumatismos cranianos ou fraturas que necessitam de cirurgia; lesões de Articulação Têmporo-Mandibular (ATM); traumas faciais; deve-se chamar a polícia (PARANÁ, 2012). Enquanto ao sigilo profissional, um dos fatores que deixa os dentistas inseguros em como proceder diante de um caso de violência doméstica. É de extrema importância manter o sigilo profissional, preservando a dignidade, o vínculo, o respeito e a confiança entre a paciente e o profissional. Entretanto, em casos de violência doméstica contra mulher, a quebra do sigilo profissional desde que seja ao caso específico, realizando a comunicação às autoridades competentes, não é enquadrado como infração ética. Possuindo ainda, amparo legal, para que o Cirurgião-Dentista não seja prejudicado (SALES-PERES, 2010).

É importante que o Cirurgião-Dentista saiba também como referenciar essa vítima/paciente, ou seja, orientar onde ela pode buscar a Rede de Apoio à mulher; se necessário, encaminhar para atendimento jurídico e social; informar e orientar a vítima para que registre um boletim de ocorrência na delegacia mais próxima (PARANÁ, 2012).

\section{CONCLUSÕES}

O desenvolvimento do presente estudo possibilitou, primeiramente, uma análise sobre a violência contra mulher, com enfoque na violência doméstica. Buscando compreender o fato de ela ter sido tão negligenciada pela sociedade e de quando começou a ganhar visibilidade, até ser considerada um problema de saúde pública. Desta forma, é importante o profissional entender o que é a violência doméstica, os seus tipos e as leis que regem. Pois não há como identificar uma vítima sem ter essa noção e conhecimento.

O Cirurgião-Dentista (CD) pode se deparar com pacientes que são vítimas não assumidas, tanto no seu consultório como no Sistema Único de Saúde (SUS) e na Estratégia Saúde da Família (ESF), visto que, as maiores incidências de lesões são na cabeça e pescoço. Mas, o que foi observado é que poucos profissionais saberiam identificar uma mulher que sofre violência doméstica. Visando isso, foram apresentados os sinais que junto com outros fatores podem levar a identificação dessas vítimas, ressaltando também a importância do atendimento humanizado e integral, e da escuta qualificada. Para que se descubra o que há por trás de tais lesões.

Diante dessa realidade, o CD além de diagnosticar e tratar deve utilizar a notificação compulsória como uma importante ferramenta de combate e de garantia de direitos, tanto em casos confirmados como 
nos que há suspeita, ressaltando que não é uma denúncia. Contudo, o profissional deve informar a vítima sobre a importância da denúncia e sobre os serviços da rede de proteção social. A notificação é um instrumento de políticas públicas importantes, visto que, ajuda no dimensionamento dessa problemática, para que desta forma possa determinar a necessidade no investimento em políticas mais efetivas e em núcleos de vigilância. Incentivando também o respeito ao direito das mulheres. Mas para isso é necessária uma melhor preparação desses profissionais, com intuito de formar não só profissionais melhores, como mais humanos.

\section{REFERÊNCIAS}

ANTUNEZ, M. E. M.; MATHIAS, C. R. J. C.. Saúde oral e doenças sexualmente transmissíveis. Adolescência \& Saúde Rio de Janeiro, v.10, n.1, p.78-79, 2013.

CAMARGO, I. B.; OLIVEIRA, D. M.; FERNANDES, A. V.; FARIAS E. M.. Fratura parassinfisária em Mulher Vítima de Violência Doméstica: Relato de Caso. Rev. Cir. Traumatol. BucoMaxilo-Fac., Camaragibe, v.12, n.1, p.11-18, 2012

CARNEIRO, A.; FRAGA, C. K.. A Lei Maria da Penha e a proteção legal à mulher vítima em São Borja no Rio Grande do Sul: da violência denunciada à violência silenciada. Serv. Soc., v.2, n.110, 2012. DOI: http://dx.doi.org/10.1590/S0101-66282012000200008

COLOMBO. Secretaria Municipal de Saúde. Protocolo de atendimento à mulher em situação de violência: programa mulher cidadã. Colombo: SMS, 2012.

CURITIBA. Secretaria Municipal de Saúde. Atenção à mulher em situação de violência. Curitiba: Ajir, 2008.

ESSY, D. B.. A evolução histórica da violência contra a mulher no cenário brasileiro: do patriarcado à busca pela efetivação dos direitos humanos femininos. Brasília: Conteúdo Jurídico, 2017.

FIGUEIREDO, M. C.; CESAR, M. O.; SILVA, J. P.; BORBA, E. M. $B$.. Prevalência de mulheres vítimas de violência no município de Porto Alegre e a influência de suas variáveis no âmbito odontológico. RFO UPF, Passo fundo, v.17, n.3, p.254-260, 2012

FONSECA, D. H.; RIBEIRO, C. G.; LEAL, N. S. B.. Violência doméstica contra mulher: realidades e representações sociais. Psicologia e Sociedade, Belo Horizonte, v.24, n.2, p.307-314, 2012

GARBIN, C. A. S.; GARBIN, A. J. I.; DOSSI, A. P.; DOSSI, M. O.. Violência doméstica: análise das lesões em mulheres. Cad. Saúde Pública, Rio de Janeiro, v.22, n.12, p.2567-2573, 2006. DOI: http://dx.doi.org/10.1590/S0102-311X2006001200007

LEITE, R. M.; NORONHA, R. M. L.. A violência contra a mulher: herança histórica e reflexo das influências culturais e religiosas. Revista Direito \& Dialogicidade, Crato, v.6, n.1, p.1-15, 2015

LOPES, J. S.. Humanização do Acolhimento à Mulher Vítima de Violência Doméstica: Revisão Sistemática a Partir da Promulgação da Lei Maria da Penha. Gênero \& Direito, v.5, n.1, p.282-302, 2016
LUCENA, K. D. T.; DEININGER, L. S. C.; COELHO, H. F. C. MONTEIRO, A. C. C.; VIANNA, R. P. T.; NASCIMENTO, J. A. Análise do ciclo da violência doméstica contra a mulher. J. Hum. Growth Dev., São Paulo, v.26, n.2, p.139-146, 2016. DOI: https://doi.org/10.7322/jhgd.119238

MORAES, A. F.; RIBEIRO, L.. As políticas de combate à violência contra a mulher no Brasil e a "responsabilização" dos "homens autores de violência". Sexualidad., Salud y Sociedad. (Rio J.), Rio de Janeiro, v.5, n.11, p.37-58, 2012. DOI: http://dx.doi.org/10.1590/S1984-64872012000500003

OLIVEIRA, P. P.; VIEGAS, S. M. F; SANTOS, W. J.; SILVEIRA, A. A.; ELIAS, S. C.. Mulheres vítimas de violência doméstica: uma abordagem fenomenológica. Texto \& Contexto Enfermagem, v.24, n.1, p.196-203, 2015. DOI: http://dx.doi.org/10.1590/0104-07072015002900013

PARANÁ. Secretaria da Saúde. Atenção à mulher em situação de violência: Linha Guia. Curitiba, 2012

PEDROSA, C. M.; SPINK, M. J. P.. A violência contra mulher no cotidiano dos serviços de saúde: desafios para a formação médica. Saúde soc. São Paulo, v.20, n.1, p.124135, 2011. DOI: http://dx.doi.org/10.1590/S010412902011000100015

SALES-PERES, S. H.; SALES-PERES, A.; FANTINI, A. M. FREITAS, F.; OLIVEIRA, M.; SILVA, O.; CHAGURI, R.. Sigilo profissional e valores éticos. Revista da Faculdade de Odontologia - UPF, v.13, n.1, 2010.

SALIBA, O.; GARBIN, C. A. S.; GARBIN, A. J. I.; DOSSI, A. P.. Responsabilidade do profissional de saúde sobre a notificação de casos de violência doméstica. Rev. Saúde Pública, São Paulo, v.41, n.3, p.472-477, 2007. DOI: http://dx.doi.org/10.1590/S0034-89102007000300021

SANTANA, J. L. B.; SILVA, B. S.; SANTOS, J. C.; ANDRADE, P. O.; MORENO, B. L.; CAMPELLO, R. I. C.; SOUZA, E. H. A. Lesões corporais e faciais em mulheres submetidas a exame de corpo de delito em Recife/PE, Brasil. Odontologia ClínicoCientífica, Recife, v.10, n.2, p.133-136, 2011.

SILVA, R. F.; PRADO, M. M.; GARCIA, R. R.; JÚNIOR, E. D.; DARUGE, E.. Atuação profissional do cirurgião-dentista diante da Lei Maria da Penha. Rev Sul-Bras Odontol. Joinville, v.7, n.1, p.110-116, 2010

TORNAVOI, D. C.; GALO, R.; SILVA, R. H. A.. Conhecimento de profissionais de Odontologia sobre violência doméstica. RSBO, Ribeirão Preto, v.1, n.8, p.54-59, 2011.

A CBPC - Companhia Brasileira de Produção Científica (CNPJ: 11.221.422/0001-03) detém os direitos materiais desta publicação. Os direitos referem-se à publicação do trabalho em qualquer parte do mundo, incluindo os direitos às renovações, expansões e disseminações da contribuição, bem como outros direitos subsidiários. Todos os trabalhos publicados eletronicamente poderão posteriormente ser publicados em coletâneas impressas sob coordenação da Sustenere Publishing, da Companhia Brasileira de Produção Científica e seus parceiros autorizados. Os (as) autores (as) preservam os direitos autorais, mas não têm permissão para a publicação da contribuição em outro meio, impresso ou digital, em português ou em tradução. 